\title{
Project Manager Assignment: A Strategic Perspective
}

\author{
Peerasit Patanakul ${ }^{*}$
}

Sam and Irene Black School of Business, The Pennsylvania State University, Erie, USA

\begin{abstract}
As projects are important to business success and the success or failure of a project partly depends on who manages it, assigning a project to a project manager is therefore among the strategic decisions in project management. Despite its importance, literature on project manager assignment is rather limited. In practice, with the resource constraints faced by a typical organization, making appropriate assignment decisions can be challenging. This challenge is even more paramount in a setting where project managers lead multiple, concurrent projects. Strategically speaking, management should assign projects to project managers in such a way that the assignments enhance the accomplishment of the organization's strategic objectives. This paper introduces a strategic aspect of project manager assignment. It starts with the discussion on the significance and challenges of making assignment decisions. Based on extensive research, a process including the criteria for project manager assignment is discussed. The paper also provides an overview of an optimization-based methodology for project manager assignment. Future research is suggested.
\end{abstract}

Keywords: Criteria, decision support model, project manager assignment, project success, strategic perspective.

\section{SIGNIFICANCE AND CHALLENGES OF PROJECT MANAGER ASSIGNMENTS}

It is recognized both in research and practice that having an appropriate project manager for a project can contribute to the success of the project [1]. With the significant influence of project managers to project success, an assignment of a project to a project manager becomes very critical [2]. With an appropriate assignment, a project manager is more likely to lead a project to its success and, the success of that project likely contributes to organizational performance.

In practice, making the assignment decisions is very challenging [3]. One challenge stems from lacking projects managers who have appropriate competencies for the projects. Other challenges are related to the organization's project management setting. Firstly, most organizations nowadays operate in multiple-project management environments, meaning that organizations implement several projects at the same time. Correspondingly, their project managers regularly lead simultaneous projects, termed as multiple-project managers [4]. Assigning new projects to these multiple-project managers always poses the risk of 1) an inappropriate assignment due to, e.g., the lack of the project managers' availability or 2) overloading the project managers, which may be a cause of project failure [3]. Secondly, even though project assignment is a critical decision in project management and multiple project management is a common practice, many organizations lack a formal process for project manager assignment. Further, information on an effective assignment process is limited in the literature [5].

*Address correspondence to this author at the Sam and Irene Black School of Business, The Pennsylvania State University, Erie, USA;

Tel: 814-898-6534; Fax: 814-898-6223; E-mail: pxp25@psu.edu
From strategic management literature, strategic fit or strategic alignment is viewed as having desirable performance implications [6, 7] and has been studied in many contexts. From the strategy formulation perspective, the appropriateness of a firm's strategy can be defined in terms of its fit, match, or congruence with the environmental of organizational contingencies facing the firm [8, 9]. From the strategy deployment perspective, strategic fit refers to the alignment between business strategy and functional strategy (such as IS, operation, and human resource strategies) and ultimately to the initiatives or projects [10-14]. With this, projects should be selected to support the business strategy. Considering strategic fit as a foundation, in addition to focusing on selecting the right projects that support the organization's strategic objectives, management should focus on assigning those projects to the appropriate project managers. To do so, a formal and effective assignment process is needed. This paper presents a process and methodology for project manager assignments that was developed from extensive research on this topic. The process and criteria for project manager assignment are discussed in the next section, followed by an optimization-based methodology for project manager assignment. For more information see $[5,15]$. Future research is proposed in the last section of the paper.

\section{PROCESS AND CRITERIA FOR PROJECT MANAGER ASSIGNMENTS}

Process and criteria for project manager assignments presented in this section were developed based on extensive case study research with six-market leading organizations in the US. Exhibit 1 illustrates a framework for project manager assignments including assignment process and criteria. More discussion on this topic can be found in publications of Patanakul and Milosevic [5] and Patanakul, Milosevic, and Anderson [15]. 




Exhibit 1. A framework for project manager assignments. Source: [15].

Findings from the case study research suggests that, the criteria for project manager assignments can typically be arranged into four specific groups: organizational strategic elements, project requirements, project managers' competencies, and organizational/personal limitations [5]. These criteria are used in three mediating steps of the assignment process: 1) prioritizing projects and then 2) finding a good fit project managers with the projects to be assigned while 3) abiding by organizational/personal limitations. This integrated process was developed by considering strategic fit as a foundation. It represents a strategic aspect of project manager assignment as it takes the strategic objectives of the organization into consideration when assigning projects to project managers. When done effectively, the project manager assignment should lead to increased performance of the projects and the organization. The mediating steps in the assignment process and related assignment criteria are described together in the following sections.

\subsection{Project Prioritization}

The first mediating step is project prioritization [5]. Using the concept of strategic fit as a foundation, prior to assigning projects to project managers, projects should be prioritized based on the degree to which they contribute to the accomplishment of the organization's strategic elements. In current business practices, many organizations, especially in high-technology industries, view projects as the engine for strategy implementation. Usually, these projects are selected according to the strategic elements of an organization, with the expectation to select those that will provide the highest value to the company's strategy. Assigning these projects without any consideration of the organization's strategic elements may post a negative impact to the organization's performance. When applying organization's strategic elements as a foundation for project prioritization, the projects that contribute more to the strategic elements should receive higher priority as they are strategically more important than the ones that contribute less. Also, it has been known that the more strategically important projects tend to contribute more to the organization's performance. With this prioritization step, management will recognize the degree to which the project is significant to the organization's performance and should therefore assign the project to the qualified project manager, providing the limitations at the organizational and personal levels (discussed later) are met.

As for the criteria for project prioritization, organizational strategic elements are often used as criteria by the 
management. In other words, projects are often prioritized based on their relative contribution to the success of these strategic elements. The organizational strategic elements that are specifically used in project assignments are the organization's goals [5]. These goals can be divided into business, operation, and technology aspects. Increased profitability, increased revenue, new markets created, increased market share, improved customer satisfaction, and new business alliances created are the business-related goals most often used. Among operation-related goals are accelerating time-to-market, enabling staff development, and balancing resource capacity. The last group of technologyrelated goals includes strengthening/leveraging technological competence, supporting techno-logical innovation, and facilitating technological knowledge transfer.

\subsection{Finding a Good Fit Between Projects and Project Managers}

The next input in making project manager assignment decision comes out of the mediating process of finding a good fit between projects and project managers [5]. This step is based on the project's requirements and project managers' competencies. The goal of this step is to achieve a fit between the level of difficulty or the demands of the project and the level of a project manager's competencies. To find a fit, the project requirements have to be clearly identified. Also, the competency levels of project managers have to be assessed to identify those managers whose competencies correspond to the requirements.

Project requirements can be assessed in many ways. The project complexity, size, and duration can be used to determine its requirements. Also, the degree of technological uncertainty, the interdependencies and interactions among projects, the degree of stakeholder involvement, including the knowledge and experience of stakeholders can be used to determine the requirements of the project. It is also important to assess project requirements in terms of risk exposure both technical and commercial risks. The organizational complexity, including the dispersion of the project team is also important to determine [5].

As for the competencies of project managers, it has been recognized both in the literature and practice that understanding the level of competencies is important for project assignments. Such an understanding helps identify the project managers who appear to possess the competencies needed to meet the identified requirements of the project. In the literature, although not specific to project assignment, the competencies of successful project managers have been widely discussed. These competencies can be grouped into administrative/process, technical, intrapersonal, interpersonal, and business competencies [16-18].

- Administrative/process competencies include the knowledge, skills, and experience of a project manager in planning and scheduling, managing resources, managing risks, monitoring and control, and the understanding of project management process.

- $\quad$ Technical competencies refer to the knowledge, and experience of a project manager related to the technical facets of the project product. This includes having knowledge of product applications, knowledge of technology and trends, knowledge of technical tools and techniques related to product development, specific knowledge of product technology, and the ability to solve technical problems.

- $\quad$ Intrapersonal competencies are qualities internal to a project manager's character. They are being organized and disciplined, responsible, proactive and ambitious, self-controlled, flexible, entrepreneurial, creative, visionary, and competitive. These competencies are the important foundation for the development of the other competencies.

- Interpersonal competencies refer to the knowledge, skills, and experience of a project manager in interacting with other project stakeholders. Interpersonal competencies include leadership, communication, team management, problem solving, and conflict management. These competencies are essential to project managers because they often have to exert their influence on project team members without having a direct authority over them.

- $\quad$ Business competencies are knowledge, skills, and experience of a project manager in addressing the business/strategic aspects of projects. They are having business sense, customer concerns, integrative capability, strategic thinking, and profit/cost consciousness. Lately, the importance of the business/strategic competencies in project management has increased as a result of the growth of the acceptance of projects as basic business vehicles in the business community.

When the project requirements and competencies of project managers are used in this step, the project that has higher requirements, for example, the one that is riskier or has a "faster" schedule, should be assigned to a more competent project manager as it is more difficult to managed than the one with the lower requirements. Logically and preferably, a more difficult to manage project is assigned to a project manager with a higher degree of competencies. Thus, a project manager with proven competencies corresponding to the identified requirements of a project is assigned.

\subsection{Recognition of Organizational/Personal Limitations}

In addition to the organizational strategic elements, project requirements, and competencies of project managers, management should also recognize the organizational/ personal limitations in project assignments [5].

Some organizational/personal limitations have been recognized as being important in the literature. Such limitations include the organization's resource capacity, interdependencies and interactions among projects, and the project manager's workload $[3,5]$. With regard to project assignments, an often-mentioned limitation is the resource capacity of project managers, especially the project managers who simultaneously lead multiple projects (multiple-project managers). Management should not assign too many projects to one multiple-project manager up to the point where he or she cannot be effective. One technical 
report showed that a multiple-project manager of four simultaneous projects may lose up to $20 \%$ of his/her time switching between tasks [19], referred to as "switchover-time loss" [20]. Given this, management does not have the luxury of assigning projects only to experienced multiple-project managers. They must consider the availability of a multipleproject manager by investigating whether or not the project manager has sufficient resource capacity to lead an additional project. It is important that the switchover-time loss from multitasking is included when determining a multiple-project manager's resource capacity. In general, the resource capacity can be measured roughly in a unit of number of projects or, as in some organizations, in a unit of number of person-hours per time period. In the prior case, depending on the complexity and technical difficulty of those projects, the limited number of projects that a multipleproject manager can simultaneously lead, can be determined, e.g. not more than five. In the latter case, the planned load of each multiple-project manager must be identified, e.g. 40 person-hours per week.

The type and phase of projects are also important factors in project assignments. Some multiple-project managers may not be able to simultaneously lead several projects of a certain type or in a certain phase. For example, a multipleproject manager may not effectively lead a breakthrough product development project and a platform project at the same time because of the technical difficulty and system complexity of those projects. Also, one consideration is that project managers often spend a large amount of time in the conceptual and planning phases of a project. Having too many projects in those phases may lead to ineffective project management.

The strength of the project team and the availability of administrative support personnel should also be determined during project manager assignments. A strong project team and the help of support staff can release a project manager from managing details such that a project manager's time spent on value-added activities can potentially increase. The interdependencies among projects are also important to be considered during project manager assignment. In several cases, this limitation leads to the assignment of several projects that have strong interdependencies to the same multiple-project manager for more efficient and effective management. In addition, another limitation that has a significant impact on the assignment is the career path of a project manager, including personal preferences. Often, management prefer to assign a project to a project manager whom they can trust to lead a project to success.

To conclude, in the step of recognizing limitations, management assess to what degree the project manager is the right person to assign the project to, given the limitations of his/her circumstances. These limitations act as criteria for determining whether the project manager is the right fit, given that the project manager's competencies match the project's requirements and the project's priority. In this step, it may happen that a certain project manager is relieved from his or her existing projects (to eliminate some limitations) in order for him/her to take on the new ones. What important in this circumstance are that the best interests of the organization (given organizational limitations) and of the multiple-project manager (given personal limitations) must be considered.

\section{PROJECT MANAGER ASSIGNMENT AND ORGANIZATION'S PERFORMANCE}

According to the framework for project manager assignment (Exhibit 1), after establishing the project assignment criteria and going through the three mediating steps, management should be able to effectively make informed decisions. The outcome of that process is the assignment of all new and existing projects to members of the pool of project managers. However, special attention should be given to strategically important projects, those that have high degree of impact on the organizational performance.

Since project performance often has a direct impact on organizational performance, in project manager assignment, the projects should go to those competent project managers who are available to lead them. In addition, when reassigning an existing project, a multiple-project manager's ability to manage the continuity of the project should be considered, especially when the project is assigned to a different project manager from its original one. In fact, a project reassignment is rather a common practice when management wants to assign a more critical project to a fully loaded, competent project manager. The way to increase the manager's availability is to unload his existing project and put it up for reassignment. In practice, changing the project manager of a project often leads to project delay, cost overruns, or quality problems $[21,22]$, which will in turn have a negative impact on the project and the organizational performance. It is important to take into consideration when assigning a project that the final outcome of the overall process is an expected increase in project and organizational performance.

\section{METHODOLOGY FOR PROJECT MANAGER ASSIGNMENTS}

This section presents a methodology for project manager assignment based on the process and criteria presented in the prior section. This project manager assignment methodology was developed using the concepts of General Assignment

Problems (GAP), an integer programming model [23], in combination with the Analytic Hierarchy Process (AHP). It is a decision-aid tool for making assignment decisions. More detail of the methodology can be found in Patanakul, Milosevic, and Anderson [15].

Following the concepts of General Assignment Problems (GAP), an optimization model for project manager assignment can be developed. The model includes the objective function and mathematical constraints. The objective function of the model can be formulated to reflect the project manager assignment such that a strategically important project $j\left(V_{j}\right)$ should be assigned to a skilled project manager $i$ whose competencies meet the requirements of project $j\left(W_{i j}\right)$. This represents the first two mediating steps in project manager assignments. In addition, the function can also be formulated to accommodate the possibility of reassignment by considering the 
effectiveness of project manager $i$ in managing discontinuity of project $j$ with respect to the organizational goal $k$. $\alpha_{i j k}$ represents the coefficient of effectiveness in managing discontinuity. The last mediating step in project manager assignment is the recognition of organizational and personal limitations. Such limitations can be formulated as mathematical constraints of the optimization model.

\subsection{Assessing Project Priority $\left(V_{j}\right)$}

Project prioritization is one of the mediating steps in the assignment process. To prioritize projects, a decision hierarchy can be constructed as shown in Exhibit 2. An organizational mission can be listed at the first level of the hierarchy, followed by the organizational goals $\left(G_{k}\right)$ on the second level. The third level contains projects $\left(P_{j}\right)$ to be assigned. By following the Analytic Hierarchy Process (AHP), e.g., performing pairwise comparisons $[24,25]$, the contribution of organizational goals to the organization mission can be identified (represented by matrix $G_{k}$ ). In addition, the AHP can help evaluate the contribution of each project to each organizational goal. To do so, pairwise comparisons between projects can be performed to evaluate their contribution to each organizational goal. As a result, the contribution of each project to each organizational goal (represented by matrix $V_{j k}$ ) can be determined. The multiplication of matrix $G_{k}$ and matrix $V_{j k}$ results in the mathematical values $\left(V_{j}\right)$ that represent the contribution of projects to the organizational mission $a k a$ project priority. In this case, strategically important projects are those that provide major contributions to the organizational mission.

\subsection{Identifying the Good Fit Between Projects and Project Managers $\left(W_{i j}\right)$ and the Effectiveness in managing Discontinuity $\left(\alpha_{i j k}\right)$}

To identify the fit between projects and project managers, the matching scores $\left(W_{i j}\right)$ between projects and project managers must be calculated.

- To do so, first, a list of project managers' competencies that should be considered during the assignment should be developed. The competencies discussed in Section 2.2 can be used as a guideline.

- Second, if these competencies are not equally important the priority level of each competency must be quantified, using e.g., pairwise comparisons.

- $\quad$ Third, this list of competencies can be used to assess the level of competencies of each project manager. One to five Likert scales can be used for such rating. For example, project manager $\mathrm{A}$ has a score of 3 in terms of knowledge of product applications, see Exhibit 3

- $\quad$ Fourth, the same list of competencies can also be used to assess the level of project requirements. By keeping project requirements in mind, for each project, the level of competencies that is required for successfully managing each project should be rated, using 1-5 Likert scales. For example, Project 1 needs a project manager who possesses leadership competency at level 5 but possesses resource management competency at level 3 .
- $\quad$ Fifth, after assessing the level of competencies of all project managers and the level of competencies required for all projects, the matching scores $\left(W_{i j}\right)$ between projects and project managers can be calculated. See the procedures in Patanakul, Milosevic, and Anderson [15].

In project manager assignment, the reassignment happens in some situations where skilled project managers are not available for the new assignments. In that situation, management may decide to release them from their existing projects so that they will have resource availability to take on the new important projects. Those existing projects are put up for reassignments. The drawback of this approach is the existing projects that are assigned to other project managers may end up with some downsides, e.g. project delay, cost overrun, or quality problems. A cause of these downsides may be the discontinuity in management because of changing the project manager [21] and their magnitude may depend on how effectively the new project manager manages the project during this transition period (represented by $\alpha_{i j k}$ ). On the other hand, if management decides not to free up the skilled project managers and assigns the new strategically important projects to the less skilled project managers who are available, these managers may not be able to manage the new projects effectively. This may result a negative impact on the project performance and eventually the performance of the organization.

To accommodate the possibility of reassignment, the coefficient of effectiveness in managing discontinuity of each project manager in each project has to be assessed. Values from 0 to 1 can be assigned as the coefficient $\left(\alpha_{i j k}\right)$ that reflects how well a project manager manages discontinuity in each project to accomplish a certain organizational goal in the case of reassignment. For example, the value 0.7 of $\alpha_{214}$ shows 70 percent effectiveness of project manager $B$ in managing the discontinuity of project 1 with respect to Goal 4.

\subsection{Recognizing Organizational/Personal Limitations}

Following the concepts of General Assignment Problems (GAP), the organizational/personal limitations can be formulated as the mathematical equations (referred to as the mathematical constraints). To do so, first, the list of limitations for project manager assignment should be compiled, using the list in Section 2.3 as guidelines. Then, each limitation on the list must be formulated into a mathematical equation. Data associated with each variable in the equation must also be collected.

One of the limitations that typically impact the project manager assignment is the resource availability of each project manager. A mathematical equation can be formulated to ensure that a project manager will not have excessive workload after the assignment is made. In other words, project $j$ can only be assigned to project manager $i$ if the project manager has sufficient time availability $\left(A_{i}\right)$. Two types of time demands upon the project manager are modeled. The first is the time demands that project $j$ requires from project manager $i\left(D_{i j}\right)$. The second time demand is a penalty function to account for the loss in productivity of 


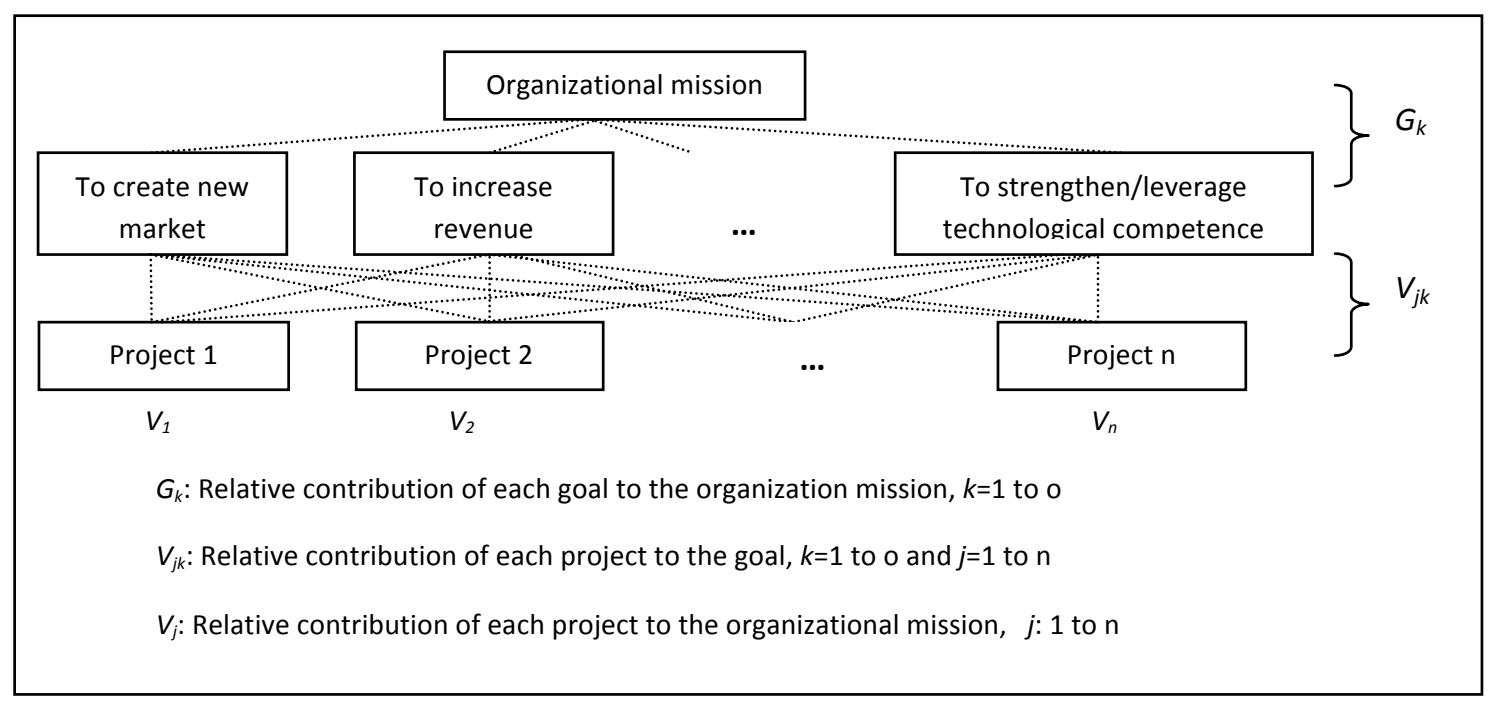

Exhibit 2. An example of the decision hierarchy for project prioritization. Source: [15].

\section{The matrices of required and available competencies}

\begin{tabular}{|c|c|c|c|c|c|c|c|c|c|c|c|c|c|}
\hline \multicolumn{2}{|c|}{ Competencies } & P1 & P2 & P3 & P4 & P5 & P6 & $\begin{array}{c}\text { PM } \\
\text { A }\end{array}$ & $\begin{array}{c}\mathrm{PM} \\
\mathrm{B}\end{array}$ & $\begin{array}{c}\mathrm{PM} \\
\mathrm{C}\end{array}$ & $\begin{array}{c}\mathrm{PM} \\
\mathrm{D}\end{array}$ & $\begin{array}{c}\mathrm{PM} \\
\mathrm{E}\end{array}$ & $\begin{array}{c}\mathrm{PM} \\
\mathrm{F}\end{array}$ \\
\hline Technical & $\begin{array}{l}\text { Knowledge of product } \\
\text { applications }\end{array}$ & 3 & 4 & 3 & 4 & 3 & 3 & 3 & 4 & 5 & 5 & 3 & 3 \\
\hline \multirow{5}{*}{$\begin{array}{l}\text { Administrative/ } \\
\text { process }\end{array}$} & Monitoring/control & 5 & 3 & 5 & 5 & 3 & 4 & 4 & 5 & 5 & 5 & 3 & 3 \\
\hline & Risk management & 5 & 4 & 5 & 5 & 3 & 4 & 4 & 5 & 5 & 5 & 4 & 3 \\
\hline & Planning/scheduling & 5 & 4 & 5 & 5 & 3 & 5 & 5 & 5 & 5 & 5 & 4 & 3 \\
\hline & Resource management & 3 & 3 & 3 & 3 & 3 & 4 & 4 & 4 & 5 & 5 & 4 & 3 \\
\hline & $\begin{array}{l}\text { Company's project } \\
\text { management process }\end{array}$ & 4 & 4 & 4 & 4 & 4 & 3 & 3 & 5 & 5 & 3 & 3 & 3 \\
\hline \multirow{5}{*}{ Intrapersonal } & Responsible & 4 & 4 & 4 & 4 & 4 & 5 & 5 & 4 & 5 & 5 & 4 & 3 \\
\hline & Proactive and ambitious & 4 & 4 & 4 & 4 & 4 & 2 & 2 & 4 & 5 & 5 & 4 & 3 \\
\hline & Mature and self-controlled & 4 & 4 & 4 & 4 & 4 & 3 & 3 & 5 & 5 & 5 & 5 & 3 \\
\hline & Organized and disciplined & 4 & 4 & 4 & 4 & 3 & 5 & 5 & 5 & 5 & 5 & 3 & 3 \\
\hline & Flexible & 5 & 5 & 5 & 5 & 5 & 2 & 2 & 5 & 5 & 5 & 5 & 3 \\
\hline \multirow{6}{*}{ Interpersonal } & Leadership & 5 & 5 & 4 & 4 & 3 & 3 & 3 & 5 & 5 & 5 & 4 & 3 \\
\hline & Communication & 4 & 4 & 4 & 4 & 4 & 2 & 2 & 5 & 5 & 5 & 4 & 3 \\
\hline & Conflict management & 4 & 4 & 4 & 4 & 4 & 1 & 1 & 3 & 5 & 5 & 4 & 3 \\
\hline & Team management & 3 & 3 & 3 & 4 & 3 & 2 & 2 & 3 & 5 & 5 & 4 & 3 \\
\hline & Negotiation & 4 & 4 & 4 & 4 & 4 & 4 & 4 & 5 & 5 & 5 & 3 & 3 \\
\hline & Problem solving & 4 & 4 & 4 & 4 & 4 & 4 & 4 & 5 & 5 & 5 & 4 & 3 \\
\hline \multirow{4}{*}{$\begin{array}{l}\text { Business/ } \\
\text { strategic }\end{array}$} & Business sense & 3 & 3 & 3 & 3 & 3 & 5 & 5 & 5 & 5 & 5 & 3 & 3 \\
\hline & Customer concern & 4 & 4 & 4 & 4 & 4 & 3 & 3 & 4 & 5 & 5 & 4 & 3 \\
\hline & Integrative capability & 4 & 3 & 3 & 5 & 3 & 4 & 4 & 5 & 5 & 5 & 4 & 3 \\
\hline & Profit / cost consciousness & 5 & 5 & 5 & 5 & 5 & 5 & 5 & 5 & 5 & 5 & 4 & 3 \\
\hline
\end{tabular}

Exhibit 3. An example of the assessment of the fit between projects and project managers. Source: [15].

project manager $i$ due to multitasking between multiple projects $\left(S_{i}\right)$. A mathematical equation representing this limitation can be formulated as $\sum_{j=1}^{m} D_{i j} X_{i j}+S_{i} \leq A_{i}$ for all $i$. $X_{i j}$ is a binary decision variable. This mathematical equation represents: "for any project manager $i$, the summation of the time demand that any project $j$ requires from project manager $i$ and the time that project manager $i$ losses due to multitasking must be less than or equal to the time that project manager $i$ has available." See more detail in Patanakul, Milosevic, and Anderson [15]. 


$$
\operatorname{Max} \sum_{i \in\{A, B, \ldots F)} \sum_{j=1}^{6} \sum_{k=1}^{4}\left(\alpha_{i j k} G_{k} V_{j k} W_{i j} X_{i j}\right) \quad \text { Objective function }
$$

Subject to:

$$
\begin{gathered}
\sum_{j=1}^{6} D_{i j} X_{i j}+S_{i} \leq A_{i} \quad \forall i \\
A_{i}=E_{i}-L_{i} \\
S_{i}=1.5 Y_{i}+4.5 Z_{i} \quad \forall i \\
N_{i}=\sum_{j=1}^{n} X_{i j}+n_{i} \quad \forall i \\
\gamma_{i} \leq 1-0.25 N_{i} \quad \forall i \\
Y_{i}=N_{i}+\gamma_{i}-1 \quad \forall \\
4 Z_{i}-Y_{i} \geq 0 \\
Z_{i}-Y_{i} \leq 0 \\
\sum_{i \in\{A, B, \ldots F\}} S C_{i j} X_{i j}=1 \quad \forall j \in \begin{array}{l}
\text { PProjects with } \\
\text { special requirements }\}
\end{array} \\
\sum_{i \in\{A, B, \ldots F\}} X_{i j}=1 \quad \forall j \\
\sum_{i \in\{A, B, \ldots F\}} X_{i j}=1 \quad \forall i \\
X_{i j}, \gamma_{i}, Z_{i}=0,1 \text { binary variables }
\end{gathered}
$$

Exhibit 4. An example of an optimization model for project manager assignment. Source: [15].

\subsection{An Optimization Model for Project Manager Assignments}

From the above discussion, the objective function of the optimization model for project manager assignment is represented by Max $\sum_{i=1}^{n} \sum_{j=1}^{m} \sum_{k=1}^{o}\left(\alpha_{i j k} G_{k} V_{j k} W_{i j} X_{i j}\right)$. The objective function of the model can be formulated to reflect the project manager assignment such that a strategically important project $j\left(V_{j}=\sum_{k=1}^{o} G_{k} V_{j k}\right)$ should be assigned to a skilled project manager $i$ whose competencies meet the project requirements $\left(W_{i j}\right)$. The function can also be formulated to accommodate the possibility of reassignment by introducing the coefficient of effectiveness in managing discontinuity of each project manager in each project, $\alpha_{i j k}$. The mathematical constraints of the optimization model are the mathematical equations formulated to represent organizational/personal limitations, discussed prior. Exhibit 4 illustrates an example of the optimization model for project manager assignment. Refer to Patanakul, Milosevic, and Anderson [15] for more detail.

\section{CONCLUSION}

This paper discusses a framework, including process, criteria, and methodology for project manager assignment. This framework can be used as a guideline for practitioners to develop an approach for project manager assignment. To develop a project assignment process, practitioners should develop a process that reflects the culture and strategy of their organization and industry. They might adapt the assignment process proposed in this study to its existing process. This adaptation should begin with the establishment of the project assignment criteria, continue with the three mediating steps, and culminate in the project assignments. When done effectively, this process may lead to the increased performance of projects and the whole organization. The process might include the followings:

First, identify potential projects to be assigned, both new and existing projects.

Second, identify the strategic elements of the organization and prioritize projects with respect to their contribution to those strategic elements.

Third, identify the project requirements and translate them into the level of project manager competencies that a project requires.

Fourth, identify project manager candidates and their level of competencies.

Fifth, determine the fit between a project and a project manager with respect to the level of competencies that the project requires and the level that the project manager possesses.

Sixth, identify the organizational/personal limitations regarding project assignments. 
Finally, assign a project to a project manager based on project priority, the fit between project and project manager, and the organizational/personal limitations. Also consider the ability of a project manager to manage the continuity of a project if he or she is assigned to lead on an on-going project that he or she has not led before. An optimization model can be developed as a decision-aid tool.

As for future research, opportunities exist in improving the model for project manager assignments. One possibility is formulating the objective function and mathematical constraints as a function of time to improve the dynamic of the model. Such a model will help promote the balanced workload of project managers over time. In addition to model development and improvement, future empirical studies can be conducted to further investigate the criteria and process for project manager assignment. Studies can be commenced to investigate the impact of project manager assignments on the project performance and the organizational performance.

\section{CONFLICT OF INTEREST}

The author confirms that this article content has no conflict of interest.

\section{ACKNOWLEDGEMENTS}

The author would like to thank Dragan Z. Milosevic and Timothy R. Anderson for their collaboration on this research.

\section{REFERENCES}

[1] Brown SL, Eisenhardt KM. Product development: past research, present findings, and future directions. Acad Manage J 1995; 20 : 343-78.

[2] Badiru AB. Project management in manufacturing and hightechnology operations. New York: John Wiley \& Sons 1996.

[3] Kuprenas JA, Jung C-L, Fakhouri AS, Jreij WG. Project manager workload-assessment of values and influences. Proj Manage J 2000; 31: 44-51.

[4] Patanakul P, Milosevic DZ. The effectiveness in managing a group of multiple projects: Factors of influence and measurement criteria. Int J Proj Manage 2009; 27: 216-33.

[5] Patanakul P, Milosevic DZ. Assigning new product projects to multiple-project managers: What market leaders do. J High Tech Manage Res 2006; 17: 53-69.
[6] Miles RE, Snow CC. Fit, failure and the hall of fame. New York: Macmillan 1994.

[7] Zajac EJ, Kraatz MS, Bresser RKF. Modeling the dynamics of strategic fit: a normative approach to strategic change. Strat Manage J 2000; 21: 429-53.

[8] Andrew KR. The concept of corporate strategy. Homewood, IL: Dow Jones Irwin 1971.

[9] Hofer C, Schendel DE. Strategy formulation: analytical concepts. St. Paul, MN: West 1978.

[10] Henderson JC, Venkatraman N. Strategic alignment: leveraging information technology for transforming organizations. IBM Sys J $1993 ; 32$.

[11] Kearns GS, Sabherwal R. Strategic alignment between business and information technology: a knowledge-based view of behaviors, outcome, and consequences. J Manage Infor Sys 2006; 23: 129-62.

[12] Byrd TA, Lewis BR, Bryan RW. The leveraging influence of strategic alignment on IT investment: an empirical examination. Infor Manage 2006; 43: 2006.

[13] Zatzick CD, Moliterno TP, Fang T. Strategic (mis)fit: the implementation of TQM in manufacturing organizations. Strat Manage J 2012; 33: 1321-30.

[14] Hsieh YH, Chen HM. Strategic fit among business competitive strategy, human resource strategy, and reward system. Acad Strat Manage J 2011; 10: 11-32.

[15] Patanakul P, Milosevic D, Anderson T. A decision support model for project manager assignments. IEEE Trans Eng Manage 2007; 54(3): 548-64.

[16] Shenhar AJ, Thamhain HJ. A new mixture of management skills: meeting the high-technology managerial challenges. Hum Sys Manage 1994; 13: 27-40.

[17] Frame JD, Building project management competence. San Francisco: Jossey-Bass Publishers 1999.

[18] Patanakul P, Milosevic DZ. A competency model for effectiveness in managing multiple projects. J High Tech Manage Res 2008; 18 : 118-31.

[19] Kapur International. Project Management Seminar Handbook. San Ramon, CA: Center for Project Management 1993.

[20] Rubinstein JS, Meyer DE, Evans JE. Executive control of cognitive process in task switching. J Exp Psych: Hum Per Perf 2001; 27: 763-97.

[21] Pennypacker JS, Dye LD. Project portfolio management and managing multiple projects: Two sides of the same coin? In: Pennypacker JS, Dye LD, Eds. Managing multiple projects. New York: Marcel Dekker Inc. 2002; pp. 1-10.

[22] McDonough(III) EF, Spital FC. Managing project portfolios. Res Tech Manage 2003; 46: 40-6.

[23] Garey MR, Johnson DS. Computers and intractability. New York: WH Freeman \& Co 1979.

[24] Saaty TL. The analtytic hierarchy process. New York: McGrawHill 1980.

[25] Kocaoglu DF. A participative approach to program evaluation, IEEE Trans Eng Manage 1983; EM30: 112-8. 